MATEC Web of Conferences 11,01009 (2014)

DOI: $10.1051 /$ matecconf / 20141101009

(C) Owned by the authors, published by EDP Sciences, 2014

\title{
Characterization of Moroccan coal waste: valorization in the elaboration of the Portland clinker
}

\author{
D.Belkheiri ${ }^{1,2}$, M.Taibi $^{1}$, A.Diouri ${ }^{2}$, A.Boukhari ${ }^{1}$, A.Aride ${ }^{1}$, O.Sassi $^{1}$ \\ ${ }^{1}$ : Laboratoire de Physico-Chimie des Matériaux Inorganiques et Organiques, Université Mohammed V Agdal, Ecole \\ Normale Supérieure Rabat Maroc \\ 2 : Laboratoire de chimie du solide appliquée, Université Mohammed V Agdal,Faculté des sciences Rabat Maroc
}

\begin{abstract}
Coal exploited in the mine of Jerada (northeast of Morocco) was accompanied by large quantities of waste. The purpose of this work is to characterize this waste with the aim of its use as a material for civil engineering. Mineral and chemical investigations on this waste in the raw state, and at different temperature of heat treatments, were carried out by various methods: X-ray fluorescence, X-ray diffraction, infrared spectroscopy. These analyzes showed that the studied waste, contain essentially a mineral part formed by silica and various clays, as well as coal's residues. The thermal investigation of waste, by differential scanning calorimetry (DSC), revealed an exothermic phenomenon attributed to the combustion of coal residues. Other phenomena were noted on the thermograms due to the mineral part transformations. In this analysis a comparison was also made with pure coal. These characteristics of coal waste encourage studying its development in reducing energy consumption in the Portland cement manufacture. Mixtures of waste with limestone or with raw cement materials were studied, and the resulting products were analyzed by different methods.
\end{abstract}

Keywords: coal, waste, clay, chemical, thermal, characterization

\section{INTRODUCTION}

Coal mining in the mine of Jerada (northeast of Morocco) was stopped in 2001. This coal was an anthracite form containing at about 2 and $5 \%$ of pyrite. Coal production was accompanied by large quantities of solid waste estimated between 15 and $20 \mathrm{Mt}^{[1]}$ and abandoned in open air in the form of a large embankment.

This waste exposed to climatic hazards conducts to serious ecological problems. It can be carried by rain into groundwater and it can also be scattered by wind. Therefore it affects the quality of air, soil and water. A study made by Bendra et $a l^{[1]}$ about water, showed that the levels of sulfates, chlorides and nitrates were above World Health Organization (WHO) standards. The presence of sulfates can be interpreted as coming from the oxidation of the pyrite $(2-5 \%$ of coal $)$ with air and water. This produces sulfuric acide (Acid Mining Drainage AMD) which affects the quality of groundwater:

$2 \mathrm{FeS}_{2}+15 / 2 \mathrm{O} 2+4 \mathrm{H}_{2} \mathrm{O} \rightarrow \mathrm{Fe}_{2} \mathrm{O}_{3}+4 \mathrm{SO}_{4}{ }^{2-}+8 \mathrm{H}^{+}$

Around the world, studies are interested in recycling and recovery of coal waste. Some of these studies are interested in their use in the field of civil engineering. Frias et $a l^{[2][3]}$ are interested on pozzolan properties of coal waste. They study the activation of kaolinite, contained in coal mining waste, to metakaolinite which can be an alternative source to obtain pozzolans .

The coal waste can be also used in the manufacture of bricks or ceramics.

A study made by Darmane ${ }^{[4]}$ et al, on the Moroccan coal waste of Jerada shows that the oxidation of pyrite produces iron (III) oxide. This study shows that small grain sizes are rich in iron oxide, and this oxide can be recycled in paint and enamelling .

The purpose of our study is to characterize the Moroccan coal waste of Jerada with the aim of its recycling or its valorisation. It is formed of an inorganic portion which prevails and an organic portion formed of coal residues. For the chemical characterization of this waste, we used different methods such as the X-ray diffraction, the X-ray fluorescence and infrared spectroscopy. To investigate the possibility of its energetic contribution, we carried out a thermal investigation using differential scanning calorimetry (DSC). Based on these characterizations of this coal 
waste, we study its recycling and recovery in the field of hydraulic materials.

\section{I- EXPERIMENT}

\section{I.1 Samples}

The considered sample of coal waste is a mixture of representative soil samples collected from different places on the embankment, and it is called coal waste and noted CW. A portion of this waste was used to prepare three samples according to their initial size. The first sample $\mathrm{CW}_{1}$ is composed of particles with an initial diameter less than $\mathrm{d}_{1}=0.16 \mathrm{~mm}$. The particles of sample noted $\mathrm{CW}_{2}$ has a diameter $0.16 \mathrm{~mm}<\mathrm{d}_{2}<10 \mathrm{~mm}$ and the third, noted $\mathrm{CW}_{3}$ has a particle size greater than $10 \mathrm{~mm}$. We also consider, as a reference, a sample of pure coal noted PC. All samples considered: $\mathrm{CW}, \mathrm{CW}_{1}, \mathrm{CW}_{2}, \mathrm{CW}_{3}$ and $\mathrm{PC}$ were crushed and sieved to the same particle size of 160 microns.

\section{I.2 Methods of analyzes}

Chemical analyzes of the samples studied were made by X-ray fluorescence with an Axios apparatus. X-ray diffraction was carried out on powder samples using SIEMENS D5000 $(\lambda(\mathrm{CuK} \alpha 1)=154,06 \mathrm{pm})$. Infrared spectra were recorded on sample and $\mathrm{KBr}$ pellet using PERKIN ELMER apparatus. Thermal analyzes of differential scanning calorimetry were performed using DSC 121 type SETARAM with heating or cooling rate of $10^{\circ} \mathrm{C} / \mathrm{min}$ (or $5^{\circ} \mathrm{C} / \mathrm{min}$ ).

\section{RESULTS AND DISCUSSION}

\section{II.1. Characterizations of the coal waste}

\section{II.1.1 Chemical analysis by X-ray fluorescence}

This analysis (XRF), for the samples $\mathrm{CW}_{1}, \mathrm{CW}_{2}, \mathrm{CW}_{3}$ and $\mathrm{CW}$, gives the weight content for the most abundant elements and the loss on ignition (LOI) . The results are summarized in table 1 .

Table1: Elemental composition (\%weight) for the samples $\mathrm{CW}_{1}, \mathrm{CW}_{2}, \mathrm{CW}_{3}$ and $\mathrm{CW}$

\begin{tabular}{lllll}
\hline Element ISample & $\mathrm{CW}$ & $\mathrm{CW}_{1}$ & $\mathrm{CW}_{2}$ & $\mathrm{CW}_{3}$ \\
\hline $\mathrm{O}$ & 51.3 & 52.2 & 59.2 & 51.9 \\
$\mathrm{Si}$ & 24.5 & 21.0 & 15.8 & 26.1 \\
$\mathrm{Al}$ & 11.6 & 11.1 & 8.62 & 11.5 \\
$\mathrm{C}$ & 2.88 & 3.90 & 11.6 & 3.26 \\
$\mathrm{Fe}$ & 3.18 & 3.48 & 1.33 & 2.66 \\
$\mathrm{~S}$ & 1.43 & 2.91 & 0.499 & 0.236 \\
$\mathrm{~K}$ & 1.86 & 1.65 & 0.946 & 1.46 \\
$\mathrm{Na}$ & 1.13 & 1.14 & 0.872 & 1.22 \\
$\mathrm{Ca}$ & 0.58 & 1.07 & 0.174 & 0.268 \\
$\mathrm{Mg}$ & 0.76 & 0.933 & 0.551 & 0.870 \\
$\mathrm{Others}$ & 0.78 & 0.617 & 0.308 & 0.526 \\
$\mathrm{LOI}$ & 10.6 & 42.7 & 14.3 & 11.9 \\
\hline
\end{tabular}

The three main oxides in the mineral part in the samples $\mathrm{CW}_{1}, \mathrm{CW}_{2, \mathrm{CW}}$ and $\mathrm{CW}$ are given in table 2 .

Table2: Predominant mineral oxides (\%weight)

\begin{tabular}{lllll}
\hline Oxide\ Sample & $\mathrm{CW}$ & $\mathrm{CW}_{1}$ & $\mathrm{CW}_{2}$ & $\mathrm{CW}_{3}$ \\
\hline $\mathrm{SiO}_{2}$ & 52.4 & 45.0 & 33.9 & 55.9 \\
$\mathrm{Al}_{2} \mathrm{O}_{3}$ & 21.9 & 20.9 & 16.3 & 21.7 \\
$\mathrm{Fe}_{2} \mathrm{O}_{3}$ & 4.55 & 4.98 & 1.91 & 3.80 \\
\hline
\end{tabular}

We note that the smallest granulometry of this coal waste $\left(\mathrm{CW}_{1}\right)$ is richer in iron oxide. This result is in agreement with the Darmane's study ${ }^{[4]}$. This sample is also richer in sulphur element.

This analysis (XRF) shows also a significant presence of carbon. The Molar ratio $\mathrm{C} / \mathrm{Si}$ ( $\mathrm{Si}$ : the most abundant) in different samples is given in table 3 .

Table3: Molar ratio C/Si in the different samples

\begin{tabular}{lllll}
\hline Sample & $\mathrm{CW}$ & $\mathrm{CW}_{1}$ & $\mathrm{CW}_{2}$ & $\mathrm{CW}_{3}$ \\
\hline Molar ratio C/Si & 0.27 & 0.43 & 1.71 & 0.29 \\
\hline
\end{tabular}

The presence of carbon can be attributed mainly to the remains of coal. This could be considered in energy intake during the combustion of coal residues.

\section{II-1-2-Analysis by X-ray diffraction}

The diffractograms of $\mathrm{CW}, \mathrm{CW}_{1}, \mathrm{CW}_{2}$, and $\mathrm{CW}_{3}$ samples show that silica is almost half of the mineral part and the rest is formed by oxides $\left(\mathrm{Fe}_{3} \mathrm{O}_{4}\right)$ and clays $(2: 1$ layer $)$ as muscovite $\left(\mathrm{H}_{2} \mathrm{KAl}_{3}\left(\mathrm{SiO}_{4}\right)_{3}\right)$, illite $\left(\left(\mathrm{K}, \mathrm{H}_{3} \mathrm{O}\right) \mathrm{Al}_{2}\right.$ $\left.\mathrm{Si}_{3} \mathrm{AlO}_{10}(\mathrm{OH})_{2}\right)$, clinochlore $1(\mathrm{MgAlFe})_{6}(\mathrm{Si}, \mathrm{Al})_{4} \mathrm{O}_{10}(\mathrm{OH}) 8$. The X-ray diffraction of pure coal shows that is amorphous.

The X-ray diffractogram of the sample $\mathrm{CW}_{2}$ is given in figure 1.

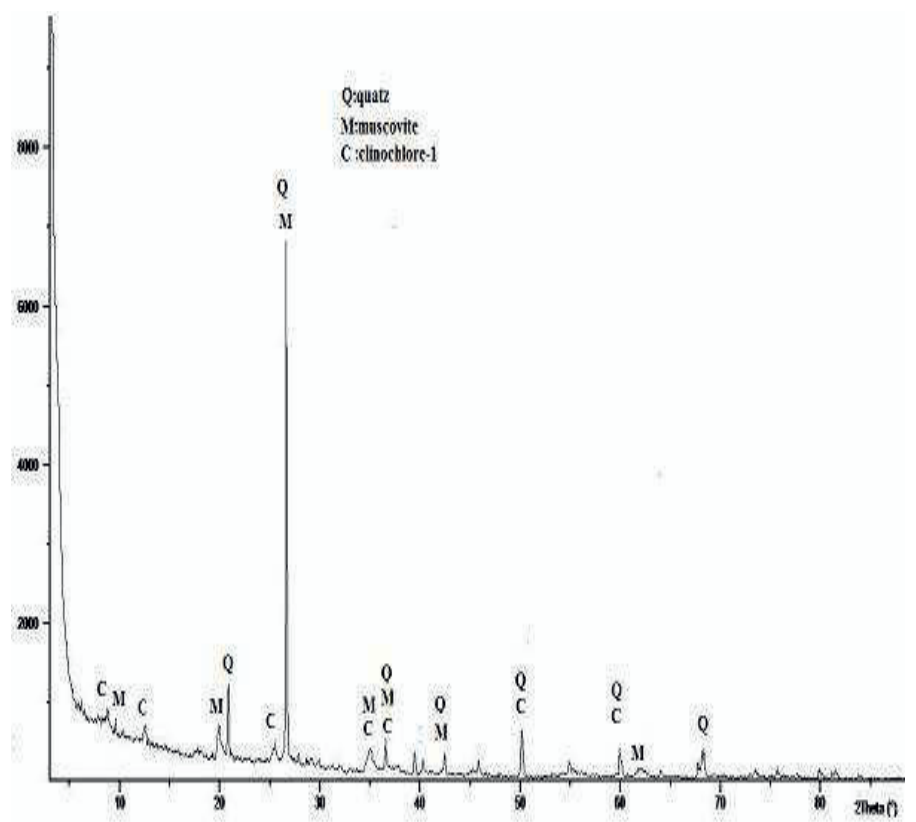

Figure1: Diffractogram of the sample CW2 
The results of the analysis by X-ray diffraction on samples are given in Table 4.

Table 4: Mineralogical composition of $\mathrm{CW}_{1}, \mathrm{CW}_{2}$ and $\mathrm{CW}_{3}$

\begin{tabular}{lll}
\hline $\mathrm{CW}_{1}$ & $\mathrm{CW}_{2}$ & $\mathrm{CW}_{3}$ \\
\hline Quartz & Quartz & Quartz \\
Magnetite & Muscovite & Muscovite \\
Illite & Clinochlore-1 & Clinochlore-1
\end{tabular}

For the samples $\mathrm{CW} 1, \mathrm{CW}_{2}$ and $\mathrm{CW} 3$ heat treatments were performed at different temperatures: 300, 500, 800 and $1000{ }^{\circ} \mathrm{C}$. Then X-ray diffraction analysis was done. Peaks corresponding to silica were present for all samples. Diffraction lines of muscovite in the spectrum disappear after $800^{\circ} \mathrm{C}$; it also noted the disappearance of the peaks of clinochlore-1

\section{II.1.3 Infrared spectroscopic analysis}

The infrared spectroscopic analysis is conducted on the CW sample. The spectrum is shown in Figure 2.

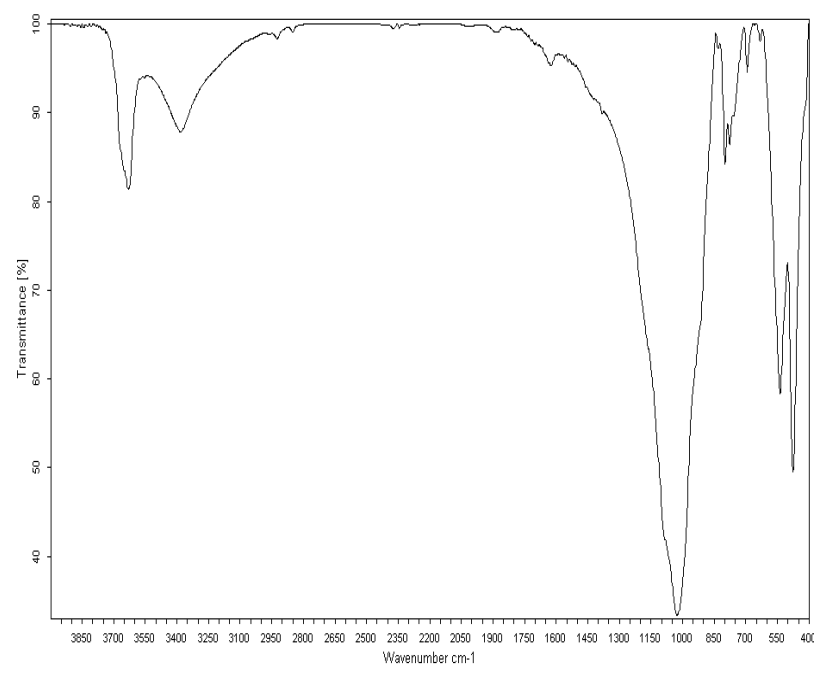

Figure 2: Infrared spectrum of CW

The observed wavenumbers can be assigned to bonds in compounds presents in the sample $\mathrm{CW}$.

Table 5: bonds concerned by infrared transmission for the sample $\mathrm{CW}$

\begin{tabular}{ll}
\hline Wavenumber (cm-1) & Attribution \\
\hline 3630 & $\mathrm{O}-\mathrm{H}$ (stretching) \\
3383 & $\mathrm{O}-\mathrm{H}, \mathrm{N}-\mathrm{H}$ \\
$2905-2850$ (weak) & $\mathrm{CH}_{3}, \mathrm{CH}_{2}, \mathrm{CH}$ aliphatic, alicyclic \\
1624 & $\mathrm{C}=\mathrm{C}$ aromatic or vinylic \\
$1090,798,778,694,476$ & $\mathrm{Si}-\mathrm{O}$ in quartz \\
1027,538 & $\mathrm{Si}-\mathrm{O}-\mathrm{Si}$ in muscovite, illite \\
476 & $\mathrm{Si}-\mathrm{O}-\mathrm{Al}$ in muscovite, illite \\
\hline
\end{tabular}

The infrared spectroscopy confirms the presence of quartz, clays (muscovite, illite) and organic compounds.
These results agree with those of X-ray diffraction and Xray fluorescence.

\section{II .1.4 DSC Analysis}

DSC analysis of coal waste is carried out with heating and cooling rate of $10{ }^{\circ} \mathrm{C} / \mathrm{min}$. In Figure 3 we give the heating and cooling thermograms of $\mathrm{CW}_{1}, \mathrm{CW}_{2}$ and $\mathrm{CW}_{3}$ in the range $20-700^{\circ} \mathrm{C}$.

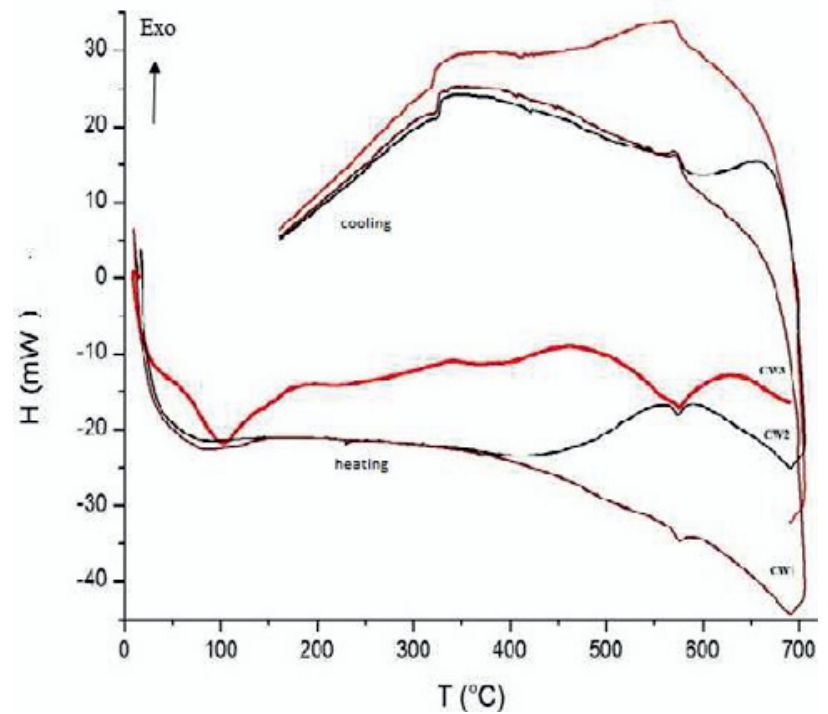

Figure 3: Thermograms of $\mathrm{CW}_{1}, \mathrm{CW}_{2}$ and $\mathrm{CW}_{3}$ samples

In the temperature range $20-700{ }^{\circ} \mathrm{C}$ we note: - A first endothermic region: between 100 and $150^{\circ} \mathrm{C}$ attributed to the leaving of free and bounded water.

- A second endothermic peak at $\mathrm{T}=570{ }^{\circ} \mathrm{C}$, which is assigned to the polymorphic transition $\alpha \rightarrow \beta$ of silica. This polymorphism is confirmed in the cooling thermogram.

- An exothermic region between 300 and $600{ }^{\circ} \mathrm{C}$ is attributed to the combustion of coal residues.

The DSC thermograms, of the three samples and of pure coal normalized to $1 \mathrm{mg}$ are given in Figure 4.

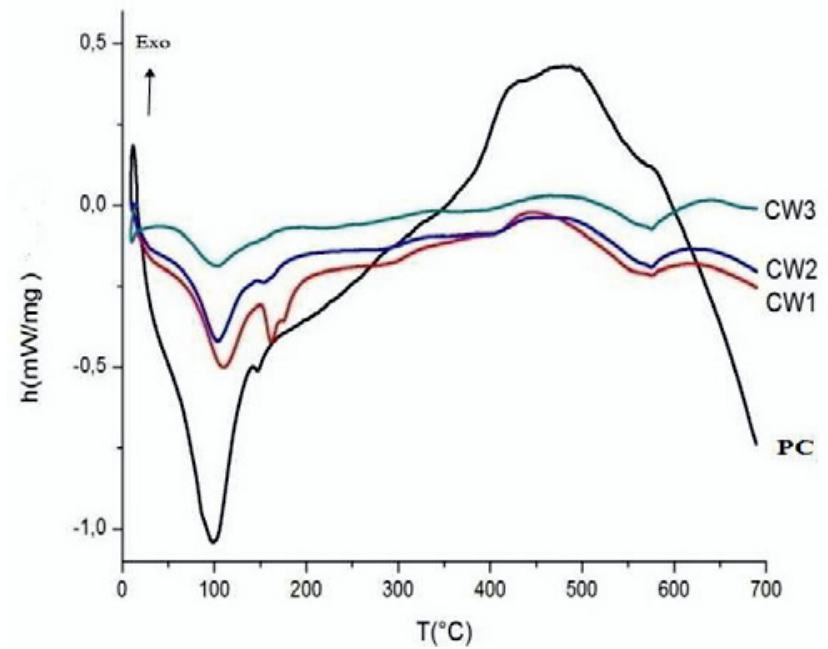

Figure 4: Normalized thermograms to $1 \mathrm{mg}$ of the sample for the studied samples

We observe that both endothermic and exothermic phenomena are more pronounced for the pure coal. We 
can observe that the pure coal presents only one phase of combustion at high temperature. The combustion of the organic part in the samples of coal waste is marked by two exothermic phenomena between 300 and $600{ }^{\circ} \mathrm{C}$ The heats realised are measured and noted $h_{1}$ and $h_{2}$ (figure 5). The heat quantities are summarized in table 6 .

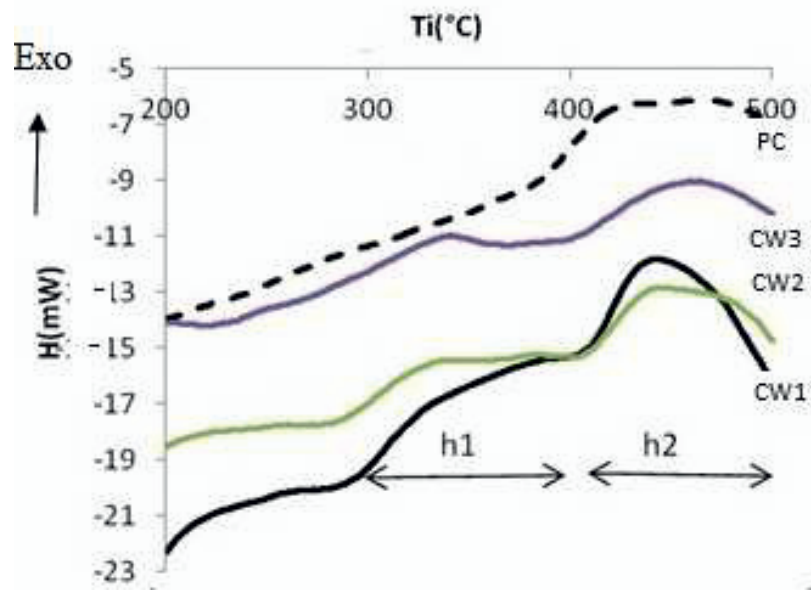

Figure 5: Exothermic effect of the samples $\mathrm{CW}_{1}, \mathrm{CW}_{2}$, $\mathrm{CW}_{3}$ and $\mathrm{PC}($ exo=up)

Table 6: Exothermic effects

\begin{tabular}{cllll}
\hline Sample & $\mathrm{PC}$ & $\mathrm{CW}_{1}$ & $\mathrm{CW}_{2}$ & $\mathrm{CW}_{3}$ \\
\hline $\mathrm{h}_{1}(\mathrm{~J} / \mathrm{g})$ & ----- & -58.87 & -59.19 & -44.71 \\
$\mathrm{~h}_{2}(\mathrm{~J} / \mathrm{g})$ & -238.17 & -8.06 & -8.14 & -6.19 \\
$\mathrm{~h}_{1}+\mathrm{h}_{2}(\mathrm{~J} / \mathrm{g})$ & -238.17 & -66.93 & -67.33 & -50.9 \\
\hline
\end{tabular}

We note that the medium granulometry $\mathrm{CW}_{2}$ is most exothermic than $\mathrm{CW}_{1}$ and $\mathrm{CW}_{3}$. This sample is richer in carbon than the others. The heat generated by the waste constitutes approximately $26 \%$ of the heat generated by the pure coal. It is therefore possible to obtain energetic advantage from the coal waste. It should be noted that the DSC experiments on the studied samples were made under conditions of incomplete combustion. The combustion is still observed after successive heating and cooling processes. The results obtained are not quantitative towards complete combustion.

In conclusion, these characterizations of coal waste show the presence of silica, clays and the presence of carbon with an exothermic potential. These results allow us to study the valuation of this caol waste in the elaboration of a clinker of cement Portland less energivore.

\section{II.2. Clinkerisation of mixtures with coal waste}

\section{II-2-1 Mixtures}

We propose to study mixtures composed of coal waste and other raw materials used in the manufacture of Portland cement. One of these mixtures noted M2 is the industrial raw meal, it is considered as a reference and is characterized by its cement ratio control: lime saturation factor $\mathrm{LSF}=99.46$, silica ratio $\mathrm{SR}=2.5$ and alumina ratio $\mathrm{AR}=1.52$.
The chemical composition of these raw materials is given in table 7 .

Table 7: Chemical composition of the raw materials

\begin{tabular}{llll}
\hline Oxide\raw & $\begin{array}{l}\text { Limestone } \\
\text { (natural) }\end{array}$ & $\begin{array}{l}\text { Calcium } \\
\text { carbonate }\end{array}$ & $\begin{array}{l}\text { Industrial raw } \\
\text { meal }\end{array}$ \\
\hline $\mathrm{SiO}_{2}$ & 13,64 & 0.1320 & 13,59 \\
$\mathrm{Al}_{2} \mathrm{O}_{3}$ & 1,29 & 0.0670 & 3,28 \\
$\mathrm{Fe}_{2} \mathrm{O}_{3}$ & 1,79 & 0 & 2,15 \\
$\mathrm{CaO}$ & 45,11 & 53.9 & 42,94 \\
Others & 1.67 & 0.60 & 2.66 \\
LOI & 36.5 & 45.3 & 35,38 \\
\hline
\end{tabular}

The others mixtures considered are noted M1 and M2:

M1: coal waste $\mathrm{CW}+$ limestone +calcium carbonate. Appropriate calculations for its composition were made to obtain modules approaching those of the reference M2. M3: coal waste $\mathrm{CW}_{2}+$ industrial raw meal. This mixture leads to a clinker which is different from the reference's clinker. The coal waste $\mathrm{CW}_{2}$ is chosen because it leads the most exothermic effect.

The chemical composition of the three mixtures is given in table 8, using cement notation for the main oxides: $\mathrm{C}(\mathrm{CaO}), \mathrm{S}\left(\mathrm{SiO}_{2}\right), \mathrm{A}\left(\mathrm{Al}_{2} \mathrm{O}_{3}\right)$ and $\mathrm{F}\left(\mathrm{Fe}_{2} \mathrm{O}_{3}\right)$.

Table 8: Composition of mixtures in the main oxide

\begin{tabular}{lllll}
\hline Mixture $\backslash$ Oxide\% & C & S & A & F \\
\hline M1 & 36.61 & 20.22 & 5.678 & 2.419 \\
M2 & 42.94 & 13.59 & 3.280 & 2.150 \\
M3 & 35.53 & 17.10 & 5.531 & 2.107 \\
\hline
\end{tabular}

The three mixtures were subjected to the same heat treatment and during the same periods : $500^{\circ} \mathrm{C}(24 \mathrm{~h}), 1000^{\circ} \mathrm{C}(12 \mathrm{~h}), 1200^{\circ} \mathrm{C}(4 \mathrm{~h}), 1300^{\circ} \mathrm{C}(40 \mathrm{~min})$ and $1400^{\circ} \mathrm{C}(40 \mathrm{~min})$. Each treatment is followed by a grinding. After heat treatment at $\mathrm{T}=1400^{\circ} \mathrm{C}$, the clinker is quenched at room temperature.

\section{II-2-2 X-ray characterisation of clinkers}

From the diffraction patterns of mixtures, we observe the calcination of limestone and lime formation between 800 and $1000^{\circ} \mathrm{C}$.

- The X-ray diffraction spectra of the three mixtures heated at $\mathrm{T}=1400{ }^{\circ} \mathrm{C}$ are given in Figure 6 . We note that the characteristic lines of lime and silica have disappeared and there is appearance of specific lines of the main cement phases $\mathrm{C}_{2} \mathrm{~S}$ (belite) and $\mathrm{C}_{3} \mathrm{~S}$ (alite) in the three mixtures.

We found that the diffractogram of the mixture corresponding to M1 (coal waste + calcium carbonate + natural limestone) is similar to that of industrial raw meal taken as reference (presence of alite, belite....). Therefore coal waste has played the role of clays.

We note also that coal waste mixed with only natural limestone leads to a clinker with different composition. The third mixture M3 leads to a clinker: $\mathrm{C}_{2} \mathrm{~S}, \mathrm{C}_{3} \mathrm{~S}$, but with a different ratio and appearence of akermanite $\left(\mathrm{Ca}_{2} \mathrm{MgSi}_{2} \mathrm{O}_{7}\right)$. 


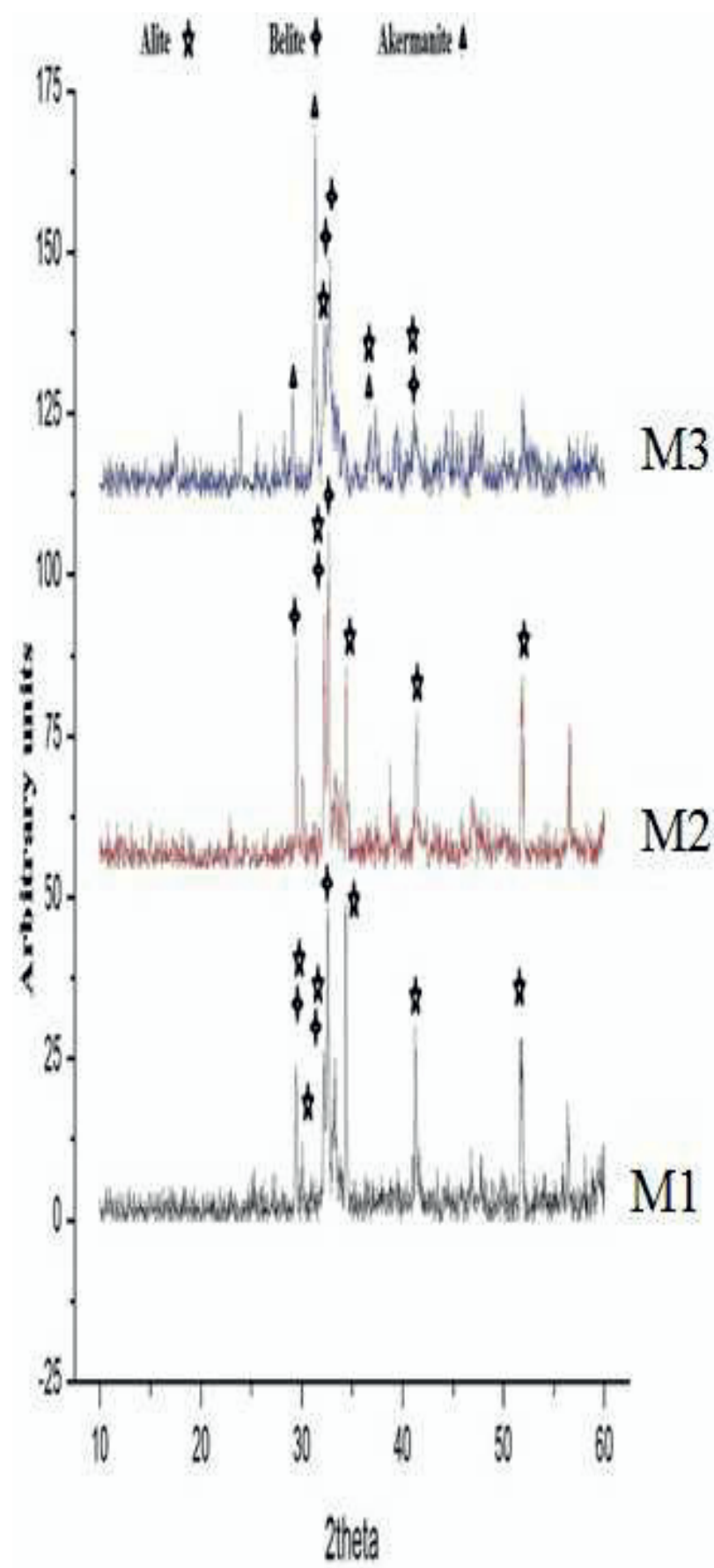

Figure 6: X-ray spectra of the three mixtures heated at $1400^{\circ} \mathrm{C}: \mathrm{M} 1\left(\mathrm{CW}+\right.$ limestone $^{\circ}$ calcite), $\mathrm{M} 2$ (industrial raw meal and M3 (CW2+industrial raw meal)

\section{II-2-3 Infrared characterization}

An infrared spectroscopy is performed for the clinker obtained from the mixture M1 (coal waste + calcium carbonate +limestone). The spectrum is given in figure7.

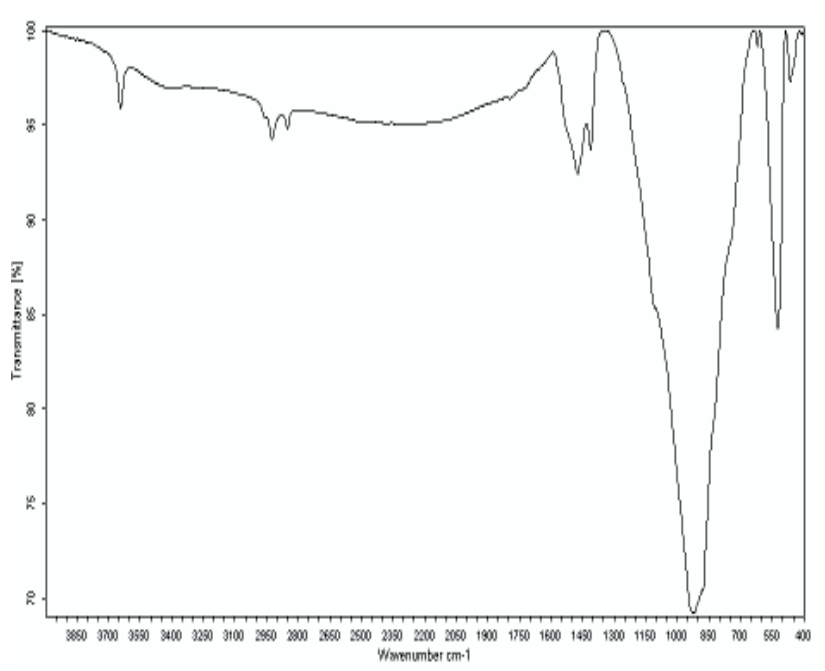

Figure 7: infrared spectroscopy of the clinker1M1400

The infrared absorption bands observed can be explained by reactions, between the compounds contained in coal waste $(\mathrm{CW})$ and lime, leading to the formation of clinker's phases. We can do attributions bands ${ }^{[6-7]}$.

$\mathrm{C}_{3} \mathrm{~S}$ : Si-O stretching at $923 \mathrm{~cm}^{-1}$ (strong) and O-Si-O bending at $523 \mathrm{~cm}^{-1}$ (medium).

$\mathrm{C}_{2} \mathrm{~S}$ : Si-0 stretching at $991,879,847 \mathrm{~cm}^{-1}$ and bending at $509 \mathrm{~cm}^{-1}$.

\section{CONCLUSION}

Mineralogical analysis shows that the waste (slag) of coal contains mostly a mineral part formed of silica and clays (2:1 layer) such as muscovite, illite and clinochlore. The organic portion is formed of coal residues. Chemical analysis shows that this waste is formed mainly by oxides of silica, aluminum, iron, magnesium, the alkaline oxide and other minor components. These oxides are generally found in building materials. So we can recycle and enhance the civil engineering sector: cements, bricks and ceramics...

Thermal analysis of the coal waste by differential scanning calorimetry (DSC) showed an exothermic phenomenon attributed to the combustion of coal residues. It is therefore possible to obtain economic benefits of energy production, especially in the context of the current energy crisis exacerbated by the decline of fossil fuels.

In particular, we can consider a valuation of coal waste in cement manufacturing since they provide raw materials silica, clay, and the combustion of coal scraps can reduce energy consumption.

This shows that the two components of waste can be recovered and recycled, and thus economic benefits (energy, civil engineering) as well as ecological benefits are performed. Thus we can reduce their environmental impact on the people's health and on nature in particular as regards the impact of coal waste on the water in this semi-arid region. 


\section{REFERENCES}

[1] B. Bendra and al, Assessing the impact of waste rocks on groundwater quality in the abandoned coal mine of Jerada city (northeastern Morocco), International Journal of Engineering Science and Technology (IJEST)(2011),p7905-7929.

[2] M. Frýas, R. Vigil de la Villa, MI. Sanchez de Rojas, C. Medina, and A. Juan Valdes . Scientific Aspects of Kaolinite Based Coal Mining Waste in Pozzolan $/ \mathrm{Ca}(\mathrm{OH})_{2}$ System. J. Am. Ceram. Soc., 95 [1] 386-391 (2012)

[3] M. Frías, M.I. Sanchez de Rojas, R. García, A. Juan Valdés, C. Medina.Effect of activated coal mining wastes on the properties of blended cement. Cement\&Concrete Composites 34(2012)678-683.

[4] Y. Darmane A. Alaoui, S. Kitane, M. Bennajah, A. Daramy, M. Cherkaoui. Recycling the slagheap of an old coal mine (Morocco), Separation and Purification Technology 68 (2009) 125-128.

[5] Y. Qiu and al, Composition and structure of Luxing coal with different particle sizes, Petroleum\&coal (2011) ISSN 1337-7027.

[6] L. Fernández-Carrasco, D. Torrens-Martín, L.M. Morales and S. Martínez-Ramírez (2012). Infrared Spectroscopy in the Analysis of Building and Construction Materials, Infrared Spectroscopy - Materials Science, Engineering and Technology, Prof.

Theophanides Theophile (Ed.), ISBN:978-953-51-05374,InTech, Available from:

http://www.intechopen.com/books/infrared-spectroscopymaterials-scienceengineeringand-technology/infrared-spectroscopy-of-cementitiousmaterials ,pp369-382.

[7] D. Govindarajan, R. Gopalakrishnan.

Spectroscopic Studies on Indian Portland Cement Hydrated with Distilled Water and Sea Water. Frontiers in Science 2011, pp: 21-27. 